\title{
Utilization trends of drugs in patients admitted with ischemic heart disease in a tertiary care teaching hospital
}

\author{
Ayan Roy', Sashi Bhushan Biswal'*, Nayan Kumar Patel², \\ Prajit Saswat Hota', Bhabagrahi Rath ${ }^{1}$
}

${ }^{1}$ Department of Pharmacology, ${ }^{2}$ Department of Cardiology, VIMSAR, Burla, Sambalpur, Odisha, India

Received: 18 February 2020

Revised: 13 April 2020

Accepted: 14 April 2020

*Correspondence:

Dr. Sashi Bhushan Biswal,

Email: drsasi12@gmail.com

Copyright: (C) the author(s), publisher and licensee Medip Academy. This is an open-access article distributed under the terms of the Creative Commons Attribution Non-Commercial License, which permits unrestricted non-commercial use, distribution, and reproduction in any medium, provided the original work is properly cited.

\section{ABSTRACT}

Background: Coronary artery disease (CAD) takes the highest toll of lives across the world as well as India. Prompt diagnosis and effective treatment is lifesaving. Drug utilization studies scrutinize the appropriateness of treatment and provide favourable feedbacks to strengthen clinical practices. Several other studies have reported underuse of four evidence-based medicines namely aspirin, $\beta$-blockers, angiotensin-converting enzyme inhibitors (ACE-I) or angiotensin receptor blockers (ARB), and statins in patients with CAD. Polypharmacy, injection overuse is some of the shortcomings. The objectives of this study was to describe treatment practices in terms of different disease spectrum and drug utilization (group-wise and individually) for inpatients with CAD using core prescription indicators by WHO.

Methods: A cross-sectional study of 4-month duration was undertaken for patients with CAD admitted to cardiology indoor of a tertiary care hospital. A total no of 143 prescriptions was screened and analyzed.

Results: Males (67.13\%) were more in number than females (32.87\%). Age group from (57-66) topped in frequency $(61.05 \%)$ ahead of (67 to 76) group (38.46\%). Average no of drugs per patient were 8.056 \pm 1.97 and $5.86 \pm 0.14$ for cardiovascular drugs. Prescription in generics (45.49\%), antibiotics (0.61\%), fixed-dose combinations (FDCs) $(0.52 \%)$ and injectables $(28.47 \%)$ were noted. The most common categories of CAD were ST-segment elevated myocardial infarction $(69.23 \%)$ followed by chronic stable angina (17.48\%). Antiplatelets (100\%), hypolipidemics $(99.3 \%)$, antianginals $(60.14 \%), \beta$-blockers $(37.06 \%)$ and ACE-I/ARBs $(27.97 \%)$ were utilized. Drugs from the national list of essential medicines were $66.49 \%$.

Conclusions: Among four evidence-based drugs, use of $\beta$-blockers and ACE-I/ARBs were inappropriately low. Polypharmacy and overuse of Injectable drugs are noted.

Keywords: Prescription auditing, Rational drug use, Drug utilization study, Coronary heart disease

\section{INTRODUCTION}

Cardiovascular disease takes the highest toll on life across the world, approximately 1 in 3 deaths are documented. India is not far behind. The burden of cardiovascular disease is increasing over the years. $85 \%$ of all cardiovascular deaths are attributed to heart attack and stroke. ${ }^{1}$ Ischemic heart disease (IHD) is the clinical spectrum of events resulting from the occluded coronary artery. High mortality and morbidity are part and parcel of IHD. Treatment involves many issues like prompt diagnosis, availability of life-saving medicines, early transfer, proper infrastructure, and above all treatment cost and patient affordability. 
Drug utilization study aims to find the appropriateness of treatment, identify shortcomings if any. WHO has devised core drug prescribing indicators meant to describe prescription practices in a representative sample of health facilities. ${ }^{2}$ Periodic evaluations of drug use in each hospital setting provide favourable feedback for treating physicians to plan, modify and strengthen clinical practices to deliver a rational and cost-effective therapy.

Literature study yielded that evidence-based secondary preventive therapies especially 4 drugs/drug groups (aspirin, $\beta$ blockers, ACE inhibitors or ARBs and statins) were under prescribed in tertiary care hospitals.,4 Polypharmacy, overuse of injections, low prescription from essential drug list are some of the shortcomings described by various studies.

\section{Aims and objective}

The aims and objectives of the study was to describe treatment practices in terms of different disease spectrum and drug utilization (group-wise and individually) for inpatients with ischemic heart disease using core prescription indicators by WHO.

\section{METHODS}

A cross-sectional study was undertaken for 4 months (July to October 2019) at VIMSAR (Veer Surendra Sai Institute of Medical Science and Research), Burla, Sambalpur in Department of Pharmacology and Cardiology. Institutional Ethics Committee permission was obtained (VIREC-19-I-S-O-151/150/19).

We went through all treatment records of inpatients of cardiology indoor within the study period diagnosed with ischemic heart disease or coronary artery disease (CAD) i.e., acute myocardial infarction (STEMI/NSTEMI) or unstable angina or chronic stable angina. 143 prescriptions in total were finally analysed after applying inclusion and exclusion criteria.

\section{Inclusion criteria}

Inclusion criteria were patients diagnosed as IHD (STEMI/unstable angina/ NSTEMI/chronic stable angina) and requiring drug treatment. Age $>18$ years of both genders. Patients admitted for at least 24 hours.

\section{Exclusion criteria}

Exclusion criteria were patients of IHD admitted for some investigations. IHD admitted for other medical problems like diarrhoea, dyselectrolytemia, etc.

Vulnerable groups and complicated post-MI cases with cardiogenic shock, severe heart failure, arrhythmia, embolic stroke, pericarditis, multi-infarct, mechanical trauma like papillary muscle rupture etc, are excluded.

\section{Data collection}

Total 143 patients' prescriptions were studied and included in the final analysis. The demographic data (age, sex), diagnosis, and presence of any other comorbid conditions were recorded from inpatient admission papers. Diagnoses were grouped in percentages according to different spectrums of IHD (STEMI, unstable angina or chronic stable angina or ACS with comorbidities). Data related to drugs prescribed were recorded as per WHO core prescription indicators i.e., average number of drugs per encounter, percentage of drugs prescribed in generics, percentage of encounter with injectables prescribed, percentage of encounters with antibiotics encountered, percentage of drugs from EDL (essential drug list). Percentage distribution of different classes of drugs (antiplatelets, antianginals, hypolipidemics, anticoagulants, antihypertensive, miscellaneous) have been studied and analysed. Individual drug distribution has been also studied.

\section{Statistical analysis}

Data were entered in MS excel 2019 and analysed. Descriptive statistics expressed in terms of actual numbers, and percentage and standard deviation. Data were compared with other prominent studies.

\section{RESULTS}

Total 143 patients' prescriptions were screened and analysed. From the demographic profile, it was observed that prevalence in males $(67.13 \%, \mathrm{n}=96)$ was more than in females $(32.87 \%, \mathrm{n}=47)$. The sex distribution is depicted in (Figure 1).

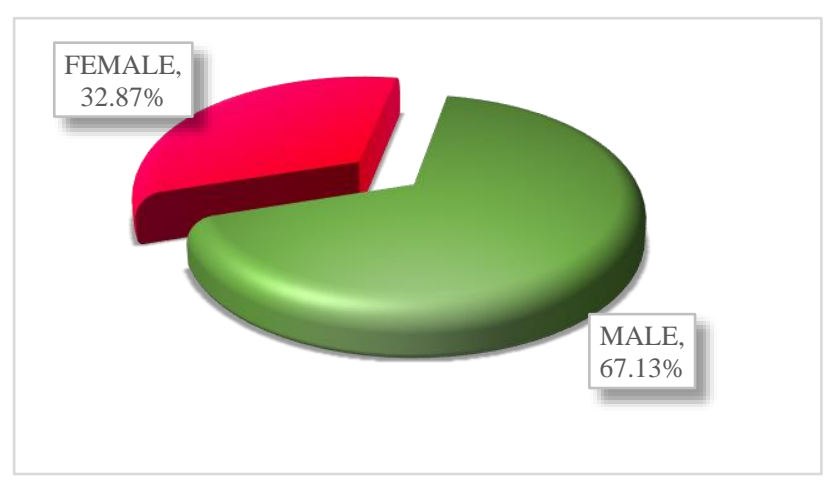

Figure 1: Gender wise distribution of enrolled patients.

Age specific distribution of patients is depicted in (Figure $2)$. Age group (56-65) topped in frequency $(n=66$, $46.15 \%)$ ahead of $(66-75)$ group $(n=61,42.66 \%)$. Mean age $64.17 \pm 6.19$ years.

The average hospital stay was documented as $4.9 \pm 0.9$ days. The common categories of IHD was ST elevated myocardial infarction STEMI $(n=99,69.23 \%)$, chronic 
stable angina $(n=25,17.48 \%)$, unstable angina $(n=13$, $9.09 \%$ ), Non-ST segment elevation myocardial infarction (NSTEMI) $(n=6,4.2 \%)$. This distribution of different categories of IHD encountered is depicted in (Figure 3).

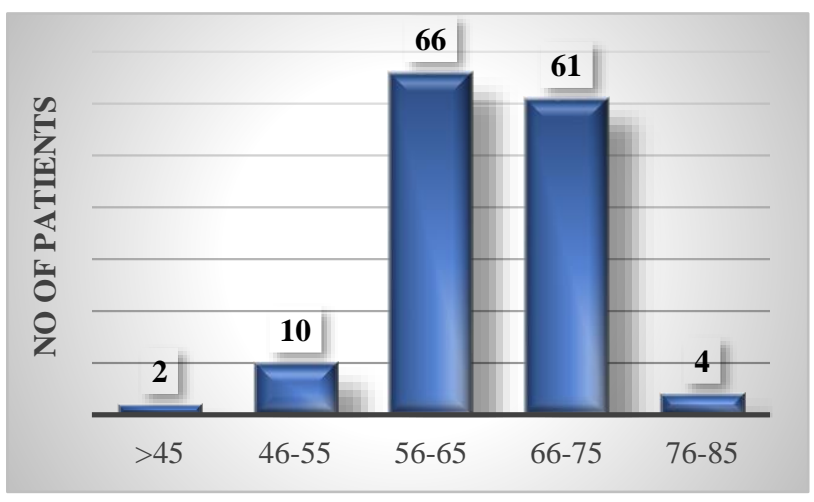

Figure 2: Age wise distribution of enrolled patients.

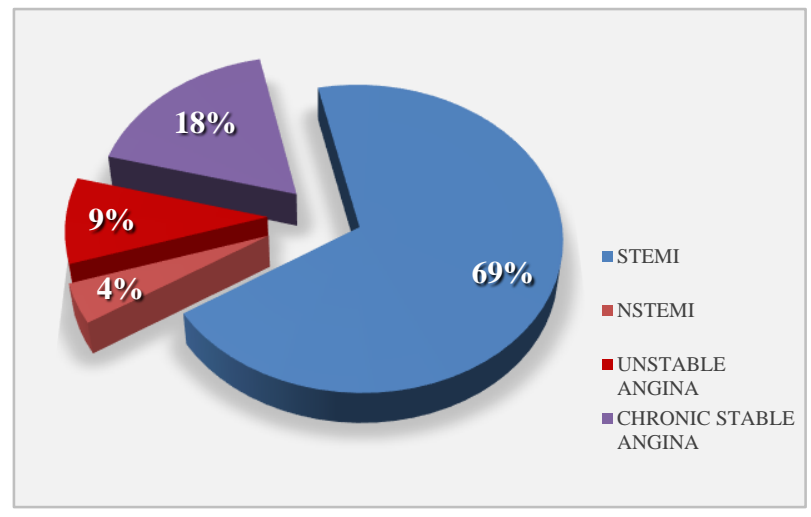

Figure 3: Percentage distribution of category of diagnosed IHD.

The categorization of patients of CAD based on the presence of concomitant diseases is depicted in (Figure 4 and Table 1). Of 143 patients, 71 (49.65\%) patients had pure coronary artery disease without any comorbidity.

Table 1: Category of study patients based on different comorbidity.

\begin{tabular}{|lll|}
\hline Comorbidity & Number & Percentage \\
\hline HTN & 35 & 24.48 \\
\hline DM & 14 & 9.79 \\
\hline HTN and DM & 23 & 16.08 \\
\hline Pure ACS & 71 & 49.65 \\
\hline
\end{tabular}

Data recorded as per WHO core prescription indicators. $77.08 \%$ of total drugs were cardiovascular drugs. Average no of prescribed drugs per patient was $8.06 \pm 1.97$ $(5.86 \pm 0.14)$ for cardiovascular drugs per prescription). $45.49 \%$ of drugs were prescribed in generics. Percentage of encounters with injectables prescribed was noted $(28.47 \%)$. Percentage of encounter with antibiotics $(0.61 \%)$, FDC (fixed-dose combinations) $(0.52 \%)$ were negligible. $66.49 \%$ of drugs were from EDL (essential drug list). Table 2, depicts the different analysed parameters of drug utilization.

Of the different cardiovascular drug utilization of antiplatelets/hypolipidemics is more than $90 \%$. Whereas prescription of beta blockers $(37.06 \%)$, ACE inhibitors (ACE-I) and ARBs (27.97\%) is low. Antianginal use was documented by nearly $60 \%$. Figure 5 , graphically depicts the individual percentage of cardiovascular drugs which is also shown in (Table 3).

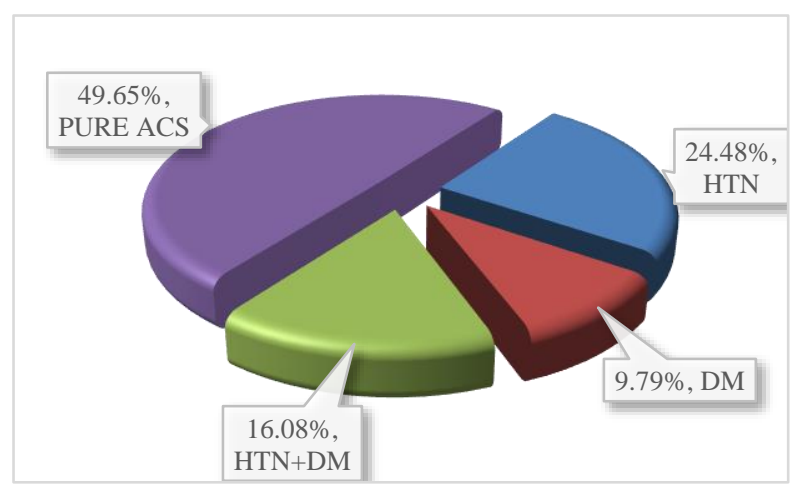

Figure 4: Category of study patients based on different comorbidity.

Table 2: Different analysed parameters of drug utilization.

\begin{tabular}{|lll|}
\hline Number & Percentage \\
\hline Total prescriptions & 143 & - \\
\hline Total no of drugs prescribed & 1152 & - \\
\hline Total no of injectables & 328 & 28.47 \\
\hline $\begin{array}{l}\text { Average no of drugs } \\
\text { prescribed per patient }\end{array}$ & $8.06 \pm 1.97$ & - \\
\hline $\begin{array}{l}\text { Total no of generic drugs } \\
\text { prescribed }\end{array}$ & 524 & 45.49 \\
\hline Total no of drugs from EDL & 766 & 66.49 \\
\hline Total no of antibiotics & 7 & 0.61 \\
\hline Total no of FDC & 6 & 0.52 \\
\hline Total no of oral meds & 802 & 67.62 \\
\hline $\begin{array}{l}\text { Total no of cardiovascular } \\
\text { drugs }\end{array}$ & 888 & 77.08 \\
\hline $\begin{array}{l}\text { Average no of } \\
\text { cardiovascular drugs per } \\
\text { patient }\end{array}$ & $5.86 \pm 0.14$ & - \\
\hline
\end{tabular}

Table 3, shows the group-wise and individual drug utilization patterns. Individual drugs have been expressed as a percentage of total prescription as well as a percentage of individual drug of the particular pharmacological group e.g., atorvastatin used $(n=141$, $98.60 \%$ of total prescription), but it was $99.3 \%$ of all hypolipidemic drugs used. Aspirin, clopidogrel were the main antiplatelets used (>90\%), atorvastatin predominated among hypolipidemics $(98.6 \%)$, ramipril in ACE I (12.59\%), metoprolol in beta blockers (30.07\%), enoxaparin $(79.72 \%)$ were some of the main drugs of their groups. 
Table 3: Group-wise and individual drug utilization patterns.

\begin{tabular}{|c|c|c|c|c|c|}
\hline Drug class & $\begin{array}{l}\text { Group total } \\
\text { drugs }\end{array}$ & Drugs & No of prescriptions & $\begin{array}{l}\text { \% against total } \\
\text { group medicines }\end{array}$ & $\begin{array}{l}\% \text { of } \\
\text { prescription }\end{array}$ \\
\hline \multirow{3}{*}{ Antiplatelets } & \multirow{3}{*}{288} & Aspirin & 143 & 50 & 100 \\
\hline & & Clopidogrel & 141 & 48.96 & 99 \\
\hline & & Ticagrelor & 4 & 1.39 & 2.80 \\
\hline \multirow{2}{*}{ Hypolipidemic } & \multirow{2}{*}{142} & Atorvastatin & 141 & 99.30 & 98.60 \\
\hline & & Rosuvastatin & 1 & 0.70 & 0.70 \\
\hline Anticoagulants & 114 & Enoxaparine & 114 & 100.00 & 79.72 \\
\hline Fibrinolytics & 59 & Streptokinase & 59 & 100 & 41.26 \\
\hline \multirow{3}{*}{ ACEI/ARBs } & \multirow{3}{*}{40} & Ramipril & 18 & 45 & 12.59 \\
\hline & & Losartan & 3 & 7.5 & 2.10 \\
\hline & & Telmisartan & 19 & 47.5 & 13.29 \\
\hline \multirow{3}{*}{ Beta-blockers } & \multirow{3}{*}{53} & Metoprolol & 43 & 68.25 & 30.07 \\
\hline & & Carvedilol & 2 & 3.17 & 1.40 \\
\hline & & Atenolol & 8 & 12.7 & 5.59 \\
\hline \multirow{2}{*}{ Diuretics } & \multirow{2}{*}{14} & Furosemide & 8 & 57.14 & 5.59 \\
\hline & & Torsemide & 6 & 42.86 & 4.20 \\
\hline CCB & 12 & Amlodipine & 12 & 100 & 8.39 \\
\hline \multirow{6}{*}{ Anti-anginal } & \multirow{6}{*}{150} & Nitroglycerine & 16 & 10.67 & 11.19 \\
\hline & & $\begin{array}{l}\text { Isosorbide } \\
\text { dinitrate }\end{array}$ & 18 & 12 & 12.59 \\
\hline & & $\begin{array}{l}\text { Isosorbide } \\
\text { mononitrate }\end{array}$ & 2 & 1.33 & 1.40 \\
\hline & & Ranolazine & 80 & 53.33 & 55.94 \\
\hline & & Ivabradine & 6 & 4 & 4.20 \\
\hline & & Nicorandil & 28 & 18.67 & 19.58 \\
\hline \multirow{3}{*}{ Inotropes } & \multirow{3}{*}{14} & Dopamine & 4 & 28.57 & 2.80 \\
\hline & & Noradrenaline & 6 & 42.87 & 4.20 \\
\hline & & Dobutamine & 4 & 28.57 & 2.80 \\
\hline
\end{tabular}

ACEI: angiotensin-converting enzyme inhibitor; ARBs: angiotensin receptor blockers.

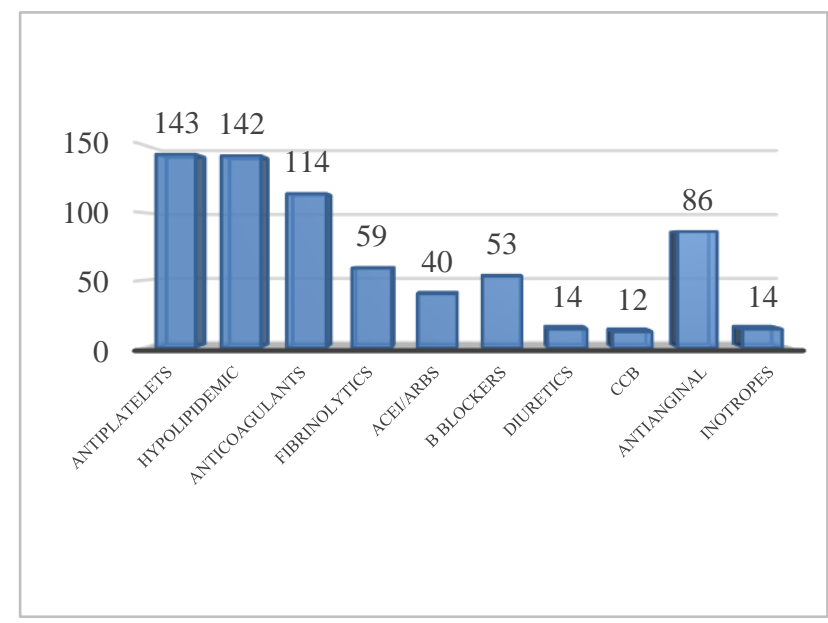

Figure 5: Various classes of cardiovascular drugs prescribed.

86 patients $(60.14 \%$ of the total prescription) received total 150 antianginal drugs. 80 patients $(53.33 \%$ of antianginals) got ranolazine, 28 patients got nicorandil (18.67\%), only $10.67 \%$ (16) nitroglycerine, $12 \%$ (18) isosorbide dinitrate, $1.33 \%$ (2) isosorbide mononitrate were prescribed. Only 6 patients were prescribed ivabradine (4\%). Diuretics and calcium channel blockers prescription is also on the lower side $<10 \%$ of the total.

Of the type 2 DM cases with IHD (total 37 cases), only 11 patients were prescribed ACE-I/ARBs. 4 cases received beta-blocker only. Of antiplatelets, only 4 prescriptions $(2.8 \%)$ ticagrelor was found other than clopidogrel, no tirofiban or eptifibatide was used. Only streptokinase has been used for thrombolysis (fibrinolysis) of acute STEMI patients. 90 out of 143 (62\%) were prescribed iv pantoprazole with clopidogrel.

\section{DISCUSSION}

In our study mean age of patient was $64.17 \pm 6.19$ years, which was higher compared to other studies done by Aswani et al $(59.06 \pm 1.8)$, Christian et al $(54.67 \pm 13.42)$ and Chaudhari et al $(57.6 \pm 11.09){ }^{5-7}$ Prevalence among males $(67.13 \%)$ was more than among females $(32.87 \%)$, which was comparable to other studies that say that cardiovascular emergencies were more common in males than females. ${ }^{8-10}$ 
Hypertension (24.48\%) and type 2 diabetes mellitus (9.79\%) and both HTN and DM (16.08\%) were the frequently associated co-morbid conditions in our study which was comparable to Saranya et al. ${ }^{8}$

The average number of drugs per prescription was $8.06 \pm 1.97(5.86 \pm 0.14)$ for cardiovascular drugs which clearly indicates polypharmacy but still was lower as compared to other studies $(9.09 \pm 2.17)$ by Saranya et al, 16.21 (5.58) by Aswani et al, $9.16(5.08 \pm 2.5)$ by Kerkar. ${ }^{8,5,11}$ The WHO standard or ideal value for the average number of drugs per prescription is 1.6-1.8. ${ }^{12}$ Cardiovascular diseases many times require urgent and aggressive treatment resulting in polypharmacy. Also, geriatric age group and its associated comorbidities increase the average drug usage per prescription which may be justified.

In our study, percentage of drugs prescribed by generic names was $45.49 \%$ compared to $1.2 \%$ (Kerkar et al) $19.5 \%$ (Christian et al) $16.88 \%$ (Choudhary et al), and $52.9 \%$ (Nagabushan et al). ${ }^{11,6,7,13}$ WHO standard being $100 \%$, doctors must be sensitized about prescribing drugs with their generic names to minimize the cost burden on the patients as well as adverse reactions due to brand name related confusion.

In the present study, drugs prescribed from the national list of essential medicines (NLEM) 2015 was $66.49 \% .{ }^{15}$ It is a good practice to adhere to EDL since this list is prepared with regard to public health relevance, evidence on efficacy and safety of the drugs, and comparative costeffectiveness. Contemporary studies document different percentages $(92.79 \%)$ Kerkar et al, $(57.06 \%)$ Aswani et al, (75.75\%) Christian et al. ${ }^{11,5,6}$

Injectables contributed around $28.47 \%$ of the total drugs prescribed. The value was lower compared to previous studies done by Aswani et al (34.99\%), Kaur et al $(75.17 \%)$ and Nagabushan et al $(100 \%))^{5,14,13}$ WHO standard for the percentage of injections per encounter is 13.4-24.1. ${ }^{12}$ Parenteral prescription adds the cost burden and also chances of adverse effects.

In comparison to other studies, our study has demonstrated negligible FDC prescription $(n=6,0.52 \%)$ even better than Kerkar et al (1.3\%), Aswani et al $(7.65 \%)$. Fewer FDC reduces cost and minimise adverse effects. ${ }^{11,5}$

In our study, antiplatelet drugs like aspirin and clopidogrel were the most commonly prescribed drugs followed by hypolipidemics $(99.3 \%)$ (atorvastatin predominantly used) which was similar to other studies. But the use of beta blockers $30.07 \%$ (40\% Kerkar et al, $65 \%$ Belhekar et al) and ACE inhibitors $12.59 \%$ (42.77\% Kerkar et al, 64\% Belhekar et al) was not adherent to the standardised national guidelines (clinical management guidelines for coronary artery disease for national programme for prevention and control of diabetes, cardiovascular disease and stroke) or 2014 ACC/AHC guidelines for ACS. ${ }^{9,11,16,17}$ Both the standardized guidelines suggest use of prasugrel and ticagrelor as superior alternates to clopidogrel especially in diabetic populations with NSTEMI/STEMI/non-responder to clopidogrel and for patients undergoing PCI (percutaneous coronary intervention). ${ }^{16,17}$ But only 4 prescriptions $(2.80 \%)$ contained these drugs.

As also previously noted, though antianginal drug use $(60.14 \%)$ was comparable to other studies $(36.66 \%$ Kerkar et al, $76 \%$ Belhekar et al), use of nitrates (oral/IV/SL) was very low $(<25 \%$ of the total prescriptions). ${ }^{11,9}$ On intragroup comparison ranolazine $53.33 \%$ and nicorandil $18.67 \%$ were prescribed far ahead of nitrates.

The limitation is that the study was undertaken for only 4 months and not close to the WHO prescribed sample size. Hence it may not have represented the total population. Secondly this data cannot be generalised for other set ups. Facility wise comparison with large multicentric study would have been better. Pharmacoeconomic parameters also could be incorporated with this study.

\section{CONCLUSION}

The over-all prescription patterns encountered in our study is optimal. However, polypharmacy, less adherence to EDL, less generic prescriptions are major shortcomings we found. Though antiplatelets, statins were maximally used (nearly 100\%), underuse of beta blockers and angiotensin-converting enzyme inhibitor (ACEI) /angiotensin receptor blockers (ARBs) is still there in tertiary care setting. We also cannot ignore the gross deviations from standard guidelines - high use of ranolazine while $80 \%$ patients were in acute ischemic group, negligible use of antiplatelets other than aspirin and clopidogrel, less than $50 \%$ use of ACEI/ARBs in diabetic population. Finally, we conclude that further drug utilization studies with different groups of IHD with larger samples will ensure more rational and safer therapy to the patient. Treatment based on an appropriate hospital protocol for the emergency management of CAD can prevent polypharmacy, unwanted drug-drug interactions.

\section{ACKNOWLEDGEMENTS}

We are thankful to the patients and staff in the cardiology department of VIMSAR, Burla. We are extremely thankful to our teachers and colleagues for their support.

Funding: No funding sources

Conflict of interest: None declared

Ethical approval: The study was approved by the Institutional Ethics Committee

\section{REFERENCES}

1. Cardiovascular diseases (CVDs). WHO Int 2019. Available at: https://www.who.int/en/news-room/ 
fact-sheets/detail/cardiovascular-diseases-(cvds).

Accessed on 24 September 2019.

2. How to Investigate Drug Use in Health Facilities: Selected Drug Use Indicators - EDM Research Series No. 007: Chapter 2: Core drug use indicators: Group 1: Prescribing indicators. Apps WHO Int 2019. Available at: https://apps.who.int/medicinedocs/en/d/ Js2289e/3.1.html. Accessed on 24 September 2019.

3. Sharma KK, Gupta R, Agrawal A. Low use of statins and other coronary secondary prevention therapies in primary and secondary care in India. Vascular Health Risk Management. 2009;5:1007-14.

4. Ajay VS, Prabhakaran D. Coronary heart disease in Indians: implications of the inter heart study. Indian $\mathrm{J}$ Med Res. 2010;132(5):561-6.

5. Bandla A, Reddy K. A Study on Prescribing Pattern of Cardiovascular Drugs and Potential Drug-Drug Interactions in An Inpatient Cardiology Unit of a Cardiac - Care Hospital at Tirupathi. Eur J Pharma Med Res. 2016;3(8):294-305.

6. Christian R, Rana D, Malhotra S, Patel V. Evaluation of rationality in prescribing, adherence to treatment guidelines, and direct cost of treatment in intensive cardiac care unit: A prospective observational study. Indian J Crit Care Med. 2014;18(5):278-84.

7. Choudhary P, Agrawal JM, Malhotra SD, Patel VJ. Drug utilization pattern in acute coronary syndrome at tertiary care hospital: a prospective cross-sectional observational study. Int J Basic Clin Pharmacol. 2016;5:513-6.

8. Lakshmi SK, Gowda HN, Sadananda KS. A study of drug utilization trends in acute coronary syndrome in intensive cardiac care unit at a tertiary care hospital, Mysore. Int J Basic Clin Pharma. 2017;6(2):344.

9. Belhekar MN, Patel TC, Singh MK, Pandit PR, Bhave KA, Redkar NN. Evaluation of prescribing pattern of drugs use in patients of coronary artery disease at a tertiary care hospital. Int $\mathrm{J}$ Basic Clin Pharma. 2018;7(9):1792.

10. Kamath A, Shanbhag T, Shenoy S. A Descriptive Study of the Influence of Age and Gender on Drug Utilization in Acute Myocardial Infarction. J Clin Diagnos Res. 2010;(4):2041-6.
11. Kerkar SS, Bhandare PN. Study of utilization trends of drugs in patients admitted with cardiovascular diseases at a tertiary care hospital in Goa. Int $\mathbf{J}$ Sci Rep. 2017;3(12):311-7.

12. Isah A, Laing R, Quick J, Mabadeje A, Santoso B, Hogerzeil H, et al. The Development of Reference Values for the WHO Health Facility Core Prescribing Indicators. West African J Pharma Drug Res. 2001;18(1).

13. Nagabushan H, Roopadevi HS, Prakash GM, Pankaja R. A prospective study of drug utilization pattern in cardiac intensive care unit at a tertiary care teaching hospital. Int J Basic Clin Pharmacol. 2015;4:579-83.

14. Kaur S, Rajagopalan S, Kaur N, Shafiq N, Bhalla A, Pandhi P, et al. Drug Utilization Study in Medical Emergency Unit of a Tertiary Care Hospital in North India. Emergency Med Int. 2014;2014:1-5.

15. National List of Essential Medicines (NLEM) 2015 India. Apps WHO Int 2017. Available at: http://apps. who.int/medicinedocs/en/m/abstract/Js23088en. Accessed on 16 October 2019.

16. Clinical Management Guidelines for Coronary Artery Disease for National Programme for Prevention and Control of Diabetes, Cardiovascular Disease and Stroke; 2010. Available at: http://www.searo.who. int/india/topics/cardiovascular_diseases/NCD_Resou rces_clinical_management_guidelines_for_cad.pdf?u $\mathrm{a}=1$. Accessed on 16 October 2019 .

17. Amsterdam E, Wenger N, Brindis R, Casey D, Ganiats T, Holmes D, et al. 2014 AHA/ACC Guideline for the Management of Patients with NonST-Elevation Acute Coronary Syndromes. Circulation. 2014;130(25):344-426.

Cite this article as: Roy A, Biswal SB, Patel NK, Hota PS, Rath B. Utilization trends of drugs in patients admitted with ischemic heart disease in a tertiary care teaching hospital. Int J Basic Clin Pharmacol 2020;9:956-61. 